\title{
Geographic Distribution of Patients Attending a Private Dental Institution
}

\author{
Dr. Aesha Zafna ${ }^{1 *}$, Dr. Ananda S. R ${ }^{2}$, Dr. Jithesh Jain ${ }^{3}$, Dr. Prasanta Majumder ${ }^{1}$, Dr. Bhakti J S \\ ${ }^{1}$ Post Graduate, Department of Public Health Dentistry, Coorg Institute of Dental Sciences (CIDS), SH 88B, Kodagu Coorg District, Virajpet, \\ Karnataka 571218, India \\ ${ }^{2}$ Professor, Department of Public Health Dentistry, Coorg Institute of Dental Sciences (CIDS), SH 88B, Kodagu Coorg District, Virajpet, Karnataka \\ 571218 , India \\ ${ }^{3}$ Professor and HOD, Department of Public Health Dentistry, Coorg Institute of Dental Sciences (CIDS), SH 88B, Kodagu Coorg Dis trict, Virajpet, \\ Karnataka 571218, India \\ ${ }^{4}$ Associate Professor, Department of Public Health Dentistry, Coorg Institute of Dental Sciences (CIDS), SH 88B, Kodagu Coorg District, Virajpet, \\ Karnataka 571218, India
}

DOI: $10.36348 / \mathrm{sb} .2019 . \mathrm{v} 05 \mathrm{i} 10.006$

| Received: 21.10.2019| Accepted: 28.10.2019| Published: 30.10.2019

*Corresponding author: Dr. Aesha Zafna

\section{Abstract}

Background: Information on dental demographic, dental needs, dental providers and the distance from the closest dental institution is necessary to plan for effective delivery of public oral health services. Geographical catchment area of dental hospitals often plays a major role in distribution of adequate health services. Aim of the study is to assess the geographical distribution of patients attending the institution to define the catchment zones and to investigate the changes in the pattern of geographic distribution of patients. 6000 new patients visiting Coorg institute of Dental Sciences and Hospital in the months of January to December in the calendar year 2018 meeting the inclusion criteria were included in the sample. Demographic details along with their location of residence were recorded. A total of 58,982 new patients visited Coorg institute of dental sciences and hospital in the calendar year of 2018.Highest number of patients were reported in the month of December followed by may indicating that hospital has a fairly large catchment zone covering a distance approximately up to $100 \mathrm{kms}$ from which $95 \%$ patients reported overlapping those of private dental clinics.

Keywords: Geographic distribution, geographic information system, GIS, density mapping, dental hospital, catchment area.

Copyright @ 2019: This is an open-access article distributed under the terms of the Creative Commons Attribution license which permits unrestricted use, distribution, and reproduction in any medium for non-commercial use (NonCommercial, or CC-BY-NC) provided the original author and source are credited.

\section{INTRODUCTION}

Coorg (anglicized name of Kodagu) known as the Scotland of India Kashmir of south , or rightly known as the Scotland of the East, is nestled amid emerald hills (390 ft above sea level) that dot the southernmost tip of Karnataka , located on the eastern slopes of the Western Ghats with a geographical area of $4,102 \mathrm{~km}$ (1,584 sq mi) [1]. The district is bordered by Dakshina Kannada district to the northwest, Hassan district to the north, Mysore district to the east, Kasaragod district in west and Kannur district of Kerala to the southwest, and Wayanad district of Kerala to the south.

The wintertime in Coorg is chilly, but quite pleasant. The average high temperature during the winter in Coorg is around $20^{\circ} \mathrm{C}$ with lows averaging in the neighborhood of $15^{\circ} \mathrm{C}$. However, during the months of December through February, the temperatures have been known to fall as low as 8 to $10^{\circ} \mathrm{C}$. During the summertime in Coorg, the temperatures generally go high as $35^{\circ} \mathrm{C}$ and drop to a low of 20 to $15^{\circ} \mathrm{C}$ in the evenings and nights. During the months of April and May, the entire town of Coorg is full with the stimulating aroma of coffee blossoms from the March blossom shower. The onset of the monsoon season is in June, when the entire town blooms greenery. Between the months of June and August, the district faces some heavy rainfall that leaves the weather humid, wet and cool. The average annual rainfall in the town ranges between 2,500 and 3,500 millimeters. The beauty of the seasonal waterfalls is best experienced during the months between July and September.

Coorg Institute of Dental Sciences (CIDS) is located at a hill in Virajpet town. The institution was set up in September 1999 and it provides a great contribution in the field of oral health care in terms of 
primary, secondary and tertiary oral health services. In addition to the routine oral care regimen therapies at a lesser price, the college also has association with different oral care programmes in collaboration with government like Dant Bhagya for dentures and Smile Train for cleft lip and palate surgeries, which can be utilized by the general population .the college also has nodal centers' in various parts of the district associated with the college which helps to meet the treatment needs of the patients. As the college provides all the adequate patient requirements emergency as well as routine dental care at an affordable cost, there are people who visit to the college for meeting their dental requirements.

In this world of technology, smart phones and computers are the most routinely used gadgets. GIS is emerging as an important novel tool in healthcare planning and understanding disparities locally, regionally, and nationally input, storage, maintenance, management, retrieval, analysis and output of location based information and therefore, it can be used to determine the geographical catchment areas of dental hospitals, so that information on local demographics is necessary to plan for the effective delivery of public oral health services $[2,3]$. Hence aim of this study was to assess the geographic distribution of patients attending the institution from surrounding villages' towns and districts.

\section{MATERIALS AND METHODS \\ Ethical Approval}

Prior to commencement of study, ethical approval was obtained from the institutional review board of coorg institute of dental sciences, virajpet.

Study Design: Descriptive cross sectional study.

\section{STUDY SETTING}

Coorg institute of dental sciences and hospital, Virajpet in the month of January 2019. The college is located approximately at a distance of $235 \mathrm{Km}$ from Bangalore.

\section{STUDY POPULATION}

A secondary data based analysis comprising 6000 patients of 18 years and above who had visited CIDS in the calendar year of 2018 from January to December .500 subjects from each month was selected using systematic sampling method.

\section{METHODOLOGY}

To have a clear knowledge about the distance travelled by the patients, the months of January December 2018 were selected randomly using institutional data base that records patient demographics. Included in the study were the 6000 new patients (patient who never visited dental college) followed by any treatment in the year 2018. The details included the study where name, age, sex and residential address of the patient. The chief complaints of the samples were also considered so as to have an insight regarding the treatment needs. The address for each patient in these samples was entered into a database and the longitude and latitude of each address was obtained through a free access geo-coding system (Google maps API). The accuracy level of this geo coding was used as a measure of integrity of the data .Only addresses geo coded to the "address ' or 'premise 'level of accuracy were included in the analysis .Using this free access geographic information system the distance between the residence of patients and institution was recorded.

\section{STATISTICAL ANALYSIS}

The data was tabulated using Ms Excel. It underwent descriptive statistical analysis using SPSS version 17. Number and percentage were used to compute results on quantitative measurement to conclude the catchment areas and the change in the coverage area of the institution.

\section{RESULTS}

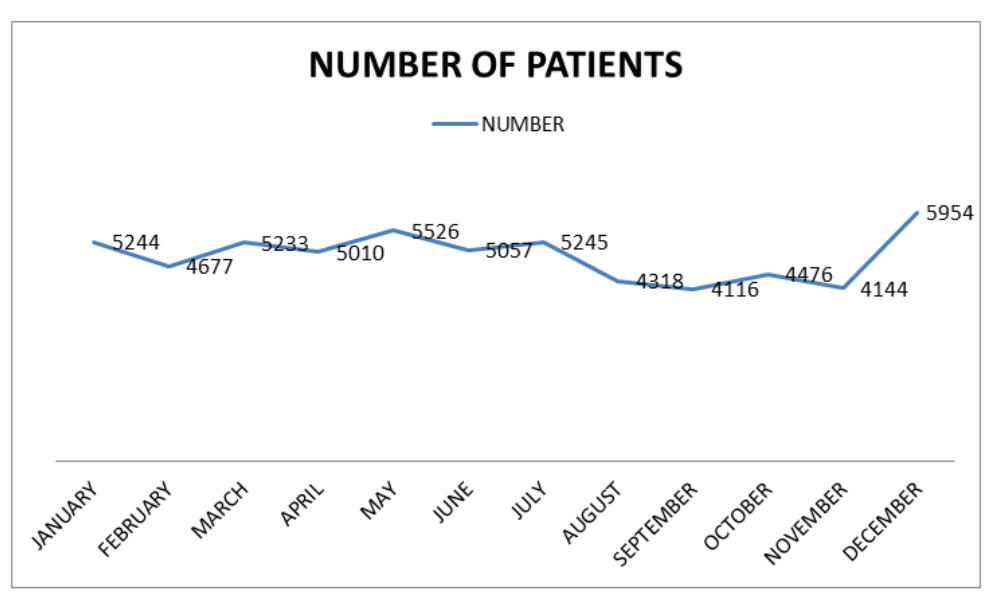

Fig-1: Distribution of number of patients reporting to dental college in 2018 
Aesha Zafna et al., Sch Bull, Oct 2019; 5(10): 580-584

A total of 58,982 new patients visited coorg institute of dental sciences and hospital in the calendar year of 2018. Highest number of patients were reported in the month of December followed by May (Figure-1).

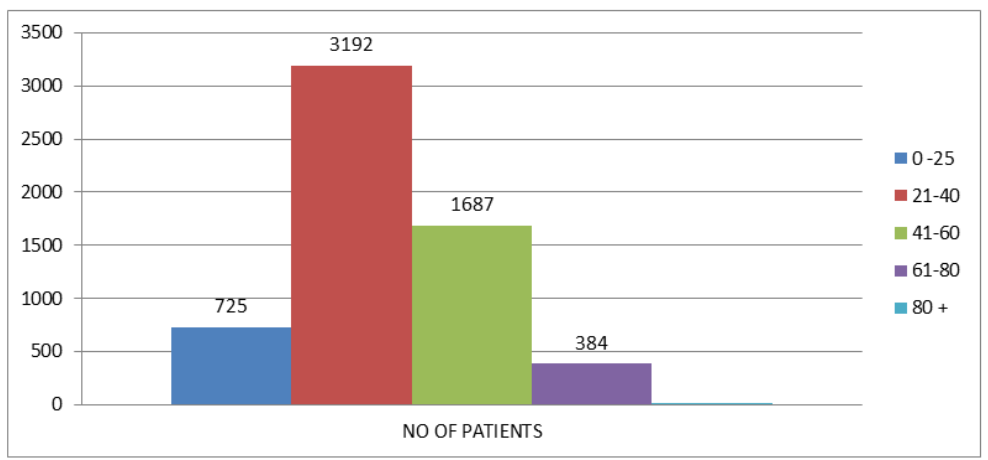

Fig-2: Age Wise Distribution of Patients

The analysis based on age group among subjects selected 6000 revealed that patients between the ages of 21- 40 years travelled the most to avail treatment followed by patients in the age group of 4160 years. Access to treatment was analyzed as a factor of straight line distance from home address to Coorg dental college. The proportion of patients living in each of these concentric areas is recorded. The data analysis was based on distance from college and age of patients receiving treatment at the institution. Age groups included are 0-20 years, 21-40 years, 41-60 years, 6180 years and 80 and above.

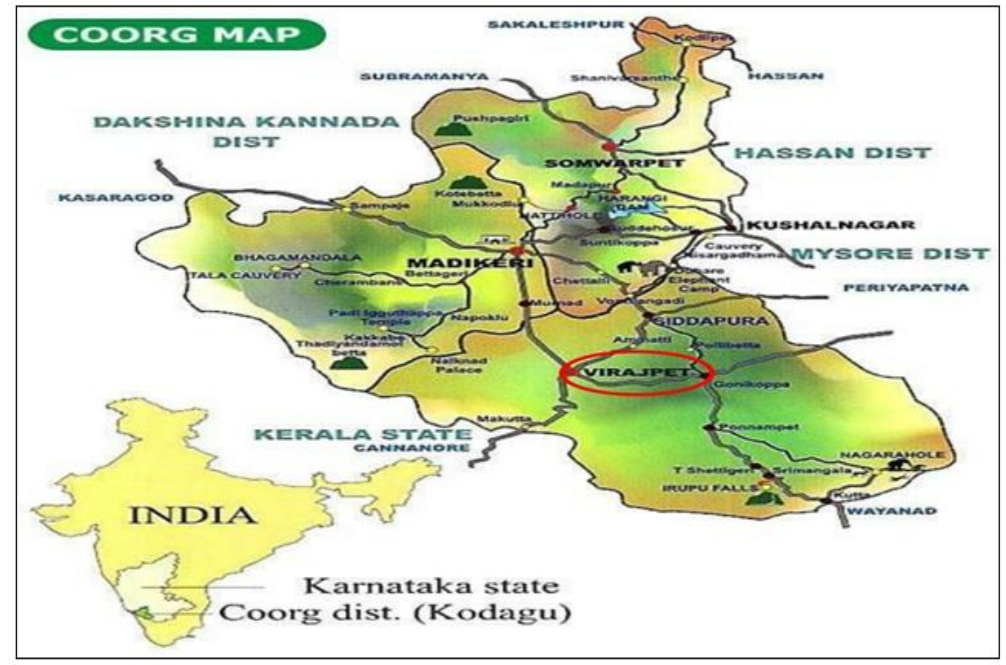

Fig-3: Map showing Coorg district

\section{DATA ANALYSIS}

Table-1: Catchment distance trends from college

\begin{tabular}{|l|l|l|}
\hline & Maximum & Minimum \\
\hline January & $10-25$ & $25-50$ \\
\hline February & $10-25$ & $25-50$ \\
\hline March & $10-25$ & $100+$ \\
\hline April & $10-25$ & $75-100$ \\
\hline May & $\mathbf{5 0 - 7 5}$ & $100+$ \\
\hline June & $10-25$ & $50-75$ \\
\hline July & $10-25$ & $50-75$ \\
\hline august & $10-25$ & $50-75$ \\
\hline September & $10-25$ & $75-100$ \\
\hline October & $10-25$ & $25-50$ \\
\hline November & $10-25$ & $25-50$ \\
\hline December & $10-25$ & $100+$ \\
\hline
\end{tabular}

Table-1 shows analysis of maximum travel distance and it is observed that in trends maximum $\mathrm{Km}$ patient reported within a distance of 50-75 Km (may), and in minimum trend was in April and September (75$100 \mathrm{Km})$.

Table-2: Distribution of study subjects according to chief complaints

\begin{tabular}{|l|l|}
\hline Pain & $\mathbf{2 4 0 0}$ \\
\hline Scaling & 940 \\
\hline Extraction & 510 \\
\hline Crown/prosthesis & 1150 \\
\hline Surgical & 160 \\
\hline Braces & 400 \\
\hline Check up /others & 440 \\
\hline
\end{tabular}


Table-2 shows categorization of subjects according to chief complaints and revealed that majority of patients seeks care for pain followed by crown and scaling respectively.

\section{DISCUSSION}

Oral health is a critical but an overlooked component of overall health and well-being among children and adults globally. Dental disease restricts activities in school, work, and home and often significantly diminishes the quality of life for many children and adults, especially those who are lowincome or uninsured [12]. Coorg institute of dental sciences located in the Kerala Karnataka border serves as a public dental hospital, primarily provide care for socio economically disadvantaged population residing in the nearby towns and villages of the district as well as people from neighboring districts.

In the present study, a vast majority of the patients came from a distance of the radius of $10-25$ $\mathrm{Km}$ to avail dental treatment. This is in accordance with the study conducted by Abhinav B et al., in Dharwad where majority of the patients reported within a distance of $6-10.9$, followed by distance of 11-15.9 $\mathrm{Km}$ [8]. Our study is also similar to study conducted at Dan kook university, periodontology department to analyze and visualize the distribution of patients visiting the, using GIS to utilize these data in patient care and treatment planning, Results showed that mean distance from each patient's regional center to the hospital was $30.94 \pm 29.62 \mathrm{~km}$ and average age of the patients was $52.41 \pm 12.97$ years and is comparable [9]. For this study it can account for the fact that probably the people belonging to lower socio economic groups travel distances in seeking regular dental care due to cost effectiveness. In a similar study in Pondicherry most of the patients availing treatment belonged to the age group of 21-40 years [13]. This may be due to the fact that in this group, it usually has working class of people who have better access and those who require higher esthetics than that of older age group.

Despite a large catchment zone, majority of the population do not seek adequate dental services provided. Hosung Shin and Han-A Cho [11] conducted a study based on secondary data to assess the Spatial barriers and the bypassing of nearby dental clinics for dental services to calculate the distance patients travel to dental clinics, the rate of bypassing nearby dental clinics and the distance covered when bypassing nearby dental clinics, and explored factors associated with patients' spatial access to dental clinics and found that median distance travelled to a dental clinic was $1.8 \mathrm{~km}$, which is farther for rural $(8.4 \mathrm{~km})$ than for urban $(1.5$ $\mathrm{km})$ patients. It can be assumed that choice of transport option as well as availability of public transport option can be a barrier in seeking regular as well as emergency dental services.
There is increasing evidence of associations between oral infections and other diseases, such as preterm, low birth weight babies, heart disease, lung disease, diabetes and stroke among adults [12]. Huge differences exist in health status including oral health between urban and rural population in developing countries. Differences also exist in health status between the urban rich and the urban poor. The finding has been mainly attributed to differences in socio economic status and limited paying capacity across populations, specifically in developing countries. Although there have been impressive advances in both dental technology and in the scientific understanding of oral diseases, significant disparities remain in both the rates of dental disease and access to dental care among subgroups of the population, especially for children and adults who live below the poverty threshold. India has 289 dental colleges with around 25,000 graduates each year [13]. Dental manpower though available yet the utilization of oral health care services is low. The reason for the low utilization of health care services being the high cost involved thereby widening the oral health differences across the social economic classes. Poor and marginalized population form majority of the population in developing countries. This undeserved population typically defined by their low incomes has poor oral health status and most of the times are unable to afford basic and emergency health care services .In India there is need for reasonably priced rural oral health service centers to provide unmet treatment needs so that the barriers in dental care can be removed and develop a positive attitude towards dental treatment. Mobile dental clinics, dental camps and outreach programmes can be conducted so that awareness can be spread regarding oral health to different stratas of the society including those of lower financial and educational background .This study thus helps in choosing areas where outreach program needs to be emphasized.

\section{CONCLUSION}

Coorg institute of Dental Sciences with its unique location had a surprisingly large catchment zone covering $100 \mathrm{~km}+$ which patients reported. The study describes geographic pattern of patient attendance and guides to focus more attention through outreach programmes to those areas from where fewer patients are reporting. Further studies however may be required to elucidate such factors.

\section{REFERENCES}

1. Gov of India /ministry of MSME /brief industrial profile of kodagu district -2018 .

2. https://en.wikipedia.org/wiki/Geographic_informat ion_system

3. Griffen, A. L. (2004). Geographic Information Systems and Health Applications. Annals of the Association of American Geographers, 94, 234236. 
4. Horner, M. W., \& Mascarenhas, A. K. (2007). Analyzing location-based accessibility to dental services: an Ohio case study. Journal of Public Health Dentistry, 67(2), 113-118.

5. Dubowitz, T., Williams, M., Steiner, E. D., Weden, M. M., Miyashiro, L., Jacobson, D., \& Lurie, N. (2011). Using geographic information systems to match local health needs with public health services and programs. American Journal of Public Health, 101(9), 1664-1665.

6. Prasannakumar, V., Vijith, H., Charutha, R., \& Geetha, N. (2011). Spatio-temporal clustering of road accidents: GIS based analysis and assessment. Procedia-Social and Behavioral Sciences, 21, 317-325.

7. Rocha, C. M., Kruger, E., McGuire, S., \& Tennant, M. (2013). The geographic distribution of patients seeking emergency dental care at the Royal Dental Hospital of Melbourne, Australia. Community dental health, 30(3), 149154.

8. Bhargava, A., Shodan, M., \& Shetty P. (2014). Geographic distribution of patients attending a private dental institution. (IOSR -JDMS), 16(4), $77-81$

9. Jeong, B., Joo, H. T., Shin, H. S., Lim, M. H., \& Park, J. C. (2016). Geographic information system analysis on the distribution of patients visiting the periodontology department at a dental college hospital. Journal of periodontal \& implant science, 46(3), 207-217.

10. Shafabakhsh, G. A., Famili, A., \& Bahadori, M. S. (2017). GIS-based spatial analysis of urban traffic accidents: Case study in Mashhad, Iran. Journal Traffic Transp Eng, 21(5): 100-102

11. Shin, H., \& Cho, H. A. (2019). Spatial barriers and the bypassing of nearby dental clinics for dental services: a secondary data analysis in Korea. BMJ open, 9(1), e024116.

12. Maheswaran, T., Ramesh, V., Krishnan, A., \& Joseph, J. (2015). Common chief complaints of patients seeking treatment in the government dental institution of Puducherry, India. $J$ Indian Acad Dent Spec Res, 2, 55-58.

13. Gambhir, R. S., Brar, P., Singh, G., Sofat, A., \& Kakar, H. (2013). Utilization of dental care: An Indian outlook. Journal of natural science, biology, and medicine, 4(2), 292-297. 